\title{
Análise temporal da qualidade da água e informações geográficas na bacia hidrográfica do Rio Passaúna
}

As Áreas de Proteção Ambientais (APA's) criadas na Região Metropolitana de Curitiba visam à proteção das bacias contribuintes das represas de abastecimento público, atuais e futuras, dentre as quais a APA do Passaúna tem um importante papel. Este trabalho teve o objetivo de avaliar a relação entre o uso e ocupação do solo e a densidade demográfica na qualidade da água para três sub-bacias hidrográfica do Rio Passaúna. Para tanto, utilizaram-se os dados históricos de parâmetros de qualidade da água das estações de amostragem do IAP (Instituto Ambiental do Paraná) disponíveis na área de pesquisa, disponíveis entre os anos de 1991 a 2016, no período da Primavera, através do quais se obteve o indicador da AlQA (Avaliação Integrada da Qualidade da Água). Tendo como referência a localização dessas estações de amostragem, definiram-se as áreas das sub-bacias que correspondem as suas respectivas áreas de escoamento. Para os anos de 2000, 2010 e 2016 foram definidas para as áreas destas sub-bacias, a densidade demográfica, o uso do solo e do atendimento da rede coletora de esgoto, os quais foram comparados aos parâmetros de qualidade da água. Na sub-bacia SB 28, onde não foi verificada a presença de áreas urbanizadas, a maior cobertura por áreas de vegetação arbórea e a melhor preservação de vegetação ripária, indicaram uma relação desses fatores com a melhor condição de qualidade verificada neste ponto de monitoramento em comparação aos demais. Na sub-bacia SB 11, fora do perímetro da APA do Passaúna, verificou-se uma pior condição de qualidade da água em relação às sub-bacias a montante a jusante da represa. Essa piora está relacionada a maior permissividade de usos e de maior presença de áreas urbanizadas e industriais. Na sub-bacia Sb 11, ainda que a condição de qualidade tenha se mantida com poluída na maior parte do tempo, apesar do aumento da urbanização e da densidade demográfica, observou-se que a ampliação do atendimento da rede de coleta de esgoto sanitário contribuiu para a melhora ou manutenção na qualidade das águas nos anos avaliados. Os resultados advertem sobre a necessidade de implementação de medidas mitigadoras de poluição como a conscientização da população, aumento dos mecanismos de controle e fiscalização dessas áreas, assim como a ampliação da rede de coleta e de tratamento de esgoto.

\section{Temporal analysis of water quality and geographical information in the hydrographic basin of Passaúna}

\begin{abstract}
The designated areas of environment protection (APA) created in the Metropolitan Region of Curitiba, are intended to protect river basins that feed into the dams providing water supply now and for future generations. Between those dams are the APA of Passauna, with a delimited hydrographic of the Passauna basin, it is an important channel for public water supply. The objective of this work is to evaluate how the use and occupation of soil and demographic density influence the quality of water in the three hydrographic sub-basins. This study made use of historical data used to determine the water quality in the sample stations of the IAP available during the spring months between 1991 to 2016. This study is based on samples collected the AIQA (Integrated evaluation of water quality) located in the water station sample collection and their respective sewage area. The data was collected over the years of 2000, 2010, 2016, and the results assessed the demographic density, use of soil and the sewage collection system near the sub-basins. In addition, the results verified the parameters to accordance with the limits established by the Class 2 qualification of the water quality as defined at the resolution CONAMA 357/2005. In the sub-basin SB 28, where it wasn't detected urbanized areas, it was identified a huge area of arboreal vegetation and a better preservation of Riparian Vegetation, therefore a better water quality in relation to the others. In the sub-basins SB 11, despite increased urbanization and population density in these areas, it was observed that increased sewage collection contributes to improve or maintain the water quality based on the date provided in the past years. The results indicate the need to implement mitigating measures to reduce water pollution, increase awareness, and improve regulation to support through inspection in these areas, as well as increase the sewage collection system in these areas.
\end{abstract}

Keywords: Management of water resources; Water quality; Public basins maintenance.

Topic: Engenharia de Recursos Hídricos

Reviewed anonymously in the process of blind peer.
Received: 02/10/2020

Approved: $24 / 11 / 2020$
Ricardo Mauricio de Freitas Andrade (iD

Universidade Tecnológica Federal do Paraná, Brasil http://lattes.cnpq.br/2134537826782280 http://orcid.org/0000-0002-7348-219X

ricardo.mfa@hotmail.com

Celimar Azambuja Teixeira (iD

Universidade Tecnológica Federal do Paraná, Brasil

http://lattes.cnpq.br/6702681725561460

http://orcid.org/0000-0002-0971-1656

celimar@utfpr.edu.br

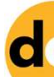

DOI: 10.6008/CBPC2179-6858.2020.006.0026
Referencing this:

ANDRADE, R. M. F.; TEIXEIRA, C. A.. Análise temporal da qualidade da água e informações geográficas na bacia hidrográfica do Rio Passaúna. Revista Ibero Americana de Ciências Ambientais, v.11, n.6, p.315331, 2020. DOI: http://doi.org/10.6008/CBPC21796858.2020 .006 .0026 


\section{INTRODUÇÃO}

As pressões pela expansão da ocupação urbana, existentes nas áreas de manancial de abastecimento público demandam políticas públicas para regulação e de uma política ambiental claramente delineada no âmbito regional. Nesse contexto a gestão dos recursos hídricos permanece, igualmente, de fundamental importância para desenvolvimento da sociedade.

Para Tundisi (2013), os usos múltiplos e competitivos da água se acentuam e colocam pressões adicionais sobre quantidade e qualidade da água e governança da água, sendo estes fatores essenciais no desenvolvimento territorial e econômico, tornando-se um elemento estratégico de grande importância. À medida que a economia se desenvolve e se diversifica, maior é a necessidade de uma gestão eficiente e participativa, de forma a contribuir para gerenciar a escassez ou o estresse hídrico, regular a demanda e compartilhar os usos múltiplos.

Conforme descrito por Andreoli et al. (2005), o rápido crescimento demográfico observado na Região Metropolitana de Curitiba (RMC) ao longo das últimas décadas, derivou em um forte crescimento das regiões periféricas das principais cidades da Grande Curitiba. Em decorrência deste processo, houve um aumento da ocupação de áreas de proteção de mananciais e várzeas. Essas ocupações geram impactos sobre a disponibilidade e qualidade da água, além da necessidade de ampliação dos sistemas de abastecimento de água, coleta de esgotos sanitários e coleta de lixo. Em decorrência desse processo, observa-se a deterioração dos corpos d'água pela ocupação de áreas importantes para recarga de aquíferos, descargas diretas de esgoto, cargas não-pontuais e escoamento superficial.

Para que se tenha um acompanhamento da evolução das condições da qualidade da água e o comportamento de determinadas variáveis em determinados pontos do manancial superficial, respectivamente, o monitoramento ambiental necessita ser realizado ao logo do tempo e do espaço servindo como instrumento de apoio a tomadas de decisão sobre os recursos hídricos (ABREU et al., 2015).

O presente estudo teve por objetivo principal avaliar os impactos dos usos dos solos em decorrência das atividades antrópicas como atividades industriais, comerciais, agrossilvopastoris e ocupação populacional, comparando as variações na qualidade de água nos anos censitários de 1991, 2000, 2010 e para o ano de 2016, sendo utilizados dados temporais das amostras coletadas pelo IAP na Bacia Hidrográfica do Rio Passaúna e de atendimento da Rede de Coleta de Esgoto (SANEPAR, 2018).

A área de pesquisa do presente trabalho é a Bacia Hidrográfica do Rio Passaúna, afluente da margem direita do Rio Iguaçu, que ocupa partes dos territórios dos municípios dos munícipios de Almirante Tamandaré, Campo Magro, Campo Largo, Curitiba e Araucária, na RMC.

Parte da referida bacia foi instituída como Área de Proteção Ambiental (APA) do Passaúna, através do Decreto Estadual $n^{\circ}$ 458/1991, alterada através da Lei Estadual 13.027/2000, cuja delimitação essencialmente se dá pelas áreas de captação da bacia a montante da área de captação do reservatório formado pela represa do Passaúna, um dos mananciais de água para abastecimento público da RMC. (COMEC, 1991; COMEC, 2000). 
A finalidade de sua implantação foi a proteção e a conservação da qualidade ambiental especialmente em relação a qualidade e quantidade da água para fins de abastecimento público, através do estabelecimento de medidas e instrumentos para gerenciar todos os fenômenos e seus conflitos sucedidos pela diversidade do ordenamento territorial e do uso e ocupação do solo (COMEC, 1991; COMEC, 2000).

\section{METODOLOGIA}

\section{Delimitação das áreas das sub-bacias analisadas}

Para a definição das áreas analisadas, definiu-se que a localização das Estações de Amostragem (Al), alocadas pelo IAP no interior da Bacia do Passaúna, representam o exutório de suas respectivas áreas de contribuição de escoamento, originado por um curso d'agua ou pelo escoamento superficial gerando no interior desta área. Deste modo, a referida bacia hidrográfica foi dividida em bacias hidrográficas menores, denominadas como sub-bacia (SB).

Para definição dos limites das sub-bacias, utilizou-se os softwares ArcView GIS 3.2 e Quantum GIS 3.6.0, com base na hidrografia e na altimetria, da Bacia do Alto Iguaçu da SUDERSHA (2000), gerados a partir da restituição aerofotogramétrica nas áreas rurais, apresentados nas Ortofotos/Cartas com escala em escala 1:10.000, e a partir de dados de projetos existentes (PARANACIDADE e IPPUC) nas áreas urbanas, com escala 1:2.000.

Os resultados que serão apresentados no item 3 se referem aos dados das seguintes sub-bacias e suas respectivas estações de amostragem no segmento anterior e no exutório da sub-bacia: SB 28 (Al 27 e Al 28) e SB 37 (Al 36 e Al 37). Na Figura 1 é possível identificar estas sub-bacias e o fluxo de suas áreas de contribuição.
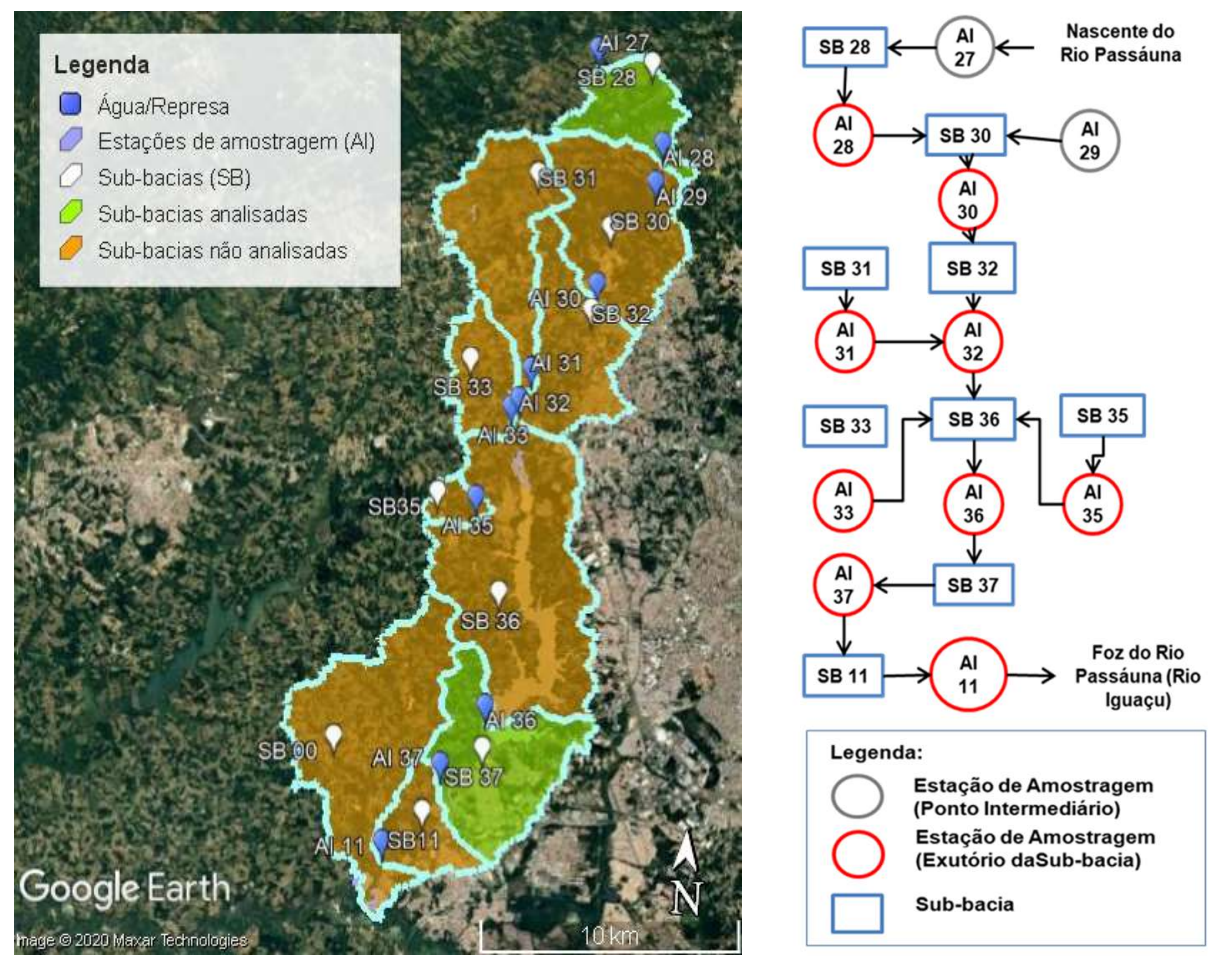

Figura 1: Delimitação das sub-bacias e fluxo de áreas de contribuições. Fonte: Google Earth Pro (2019). 
Conforme ilustrado na Figura 1, as sub-bacias não seguem uma linha sequencial contribuindo diretamente e independentemente ao rio principal, pois algumas contribuem diretamente a sua respectiva estação e outras consideram uma parte desta somadas as sub-bacias que se encontram a montante.

A escolha destas sub-bacias se deu em função de ambas receberem água com indicadores de qualidade superior no segmento anterior e por suas diferentes características demográficas, de uso e ocupação do solo.

A sub-bacia SB 28, tem características predominantemente rurais e menor densidade demográfica. A estação de Amostragem AI 27 está localizada no interior da sub-bacia SB 28 nas proximidades da nascente do Rio Passaúna no munício de Almirante Tamandaré. A estação de amostragem Al 28, através da qual foi delimitada a Sub-bacia SB 28 como área sua área de contribuição, está localizada a montante do 'Aterro Controlado da Lamenha Pequena'.

A sub-bacia SB 37, tem maior densidade demográfica e menor cobertura de Vegetação Arbórea em relação a sub-bacia SB 28. A Estação de Amostragem Al 36, localizada a jusante da Barragem, próximo a captação para abastecimento público, para a qual obtiveram-se os dados dos parâmetros de Qualidade da Água entre os anos de 1991 a 2012, visto que após o ano de 2012 as coletas foram descontinuadas.

A Estação de Amostragem Al 37, está localizada no Rio Passaúna nas proximidades do bairro Capela Velha, tem sua área de contribuição delimitada pelas sub-bacia SB 37, inserida no município de Araucária, em parte dos bairros Capela Velha e Chapada.

\section{Parâmetros de qualidade da água e Avaliação Integrada da Qualidade da Água (AIQA)}

A definição dos períodos de análise se deu em função da disponibilidade de dados das Estações de Amostragem (IAP, 2018) entre os anos de 1991 a 2016. Os parâmetros avaliados foram: oxigênio dissolvido, DBO5(Demanda biológica de oxigênio em um período de 5 dias), DQO (Demanda química de Oxigênio), nitrogênio amoniacal, nitrito, nitrato, fosfato total, Escherichia coli (E. coli), Coliformes totais e toxicidade para Daphnia magna e a Avaliação Integrada da Qualidade da Água (AIQA).

Com o objetivo de avaliar a relação entre a População e os parâmetros de qualidade das águas, avaliou-se os dados dos anos de censitários de 1991, 2000, 2010 e também para 2016, a fim de obter a comparação com resultados mais recentes. Dentre os dados históricos, foram selecionadas as amostras coletadas entre os meses de setembro a dezembro, no período da primavera, sendo aplicada a média das amostras disponíveis para cada ano nesse período.

Foi utilizada a Avaliação Integrada da Qualidade da Água (AIQA) conforme metodologia descrita por IAP (2005), cujo objetivo é fornecer informações sobre a qualidade das águas através da consideração as diversas dimensões elementos de diferentes naturezas. No cálculo do AIQA avaliaram-se três diferentes classes da qualidade. A avaliação físico-química tem por objetivo a quantificação da carga orgânica presente nos cursos d'água. A avaliação bacteriológica complementa esta análise pela indicação do grau de contaminação das amostras por coliformes. A avaliação ecotoxicológica avalia o efeito nocivo de agentes físicos ou químicos presentes na amostra ao microcrustáceo aquático Daphnia magna (bioindicador). 
A condição de Qualidade da Água definida através do AIQA, varia de 'Muito Boa' até 'Extremamente Poluída", a qual é divida em faixas de valores encontrados para a distância L, representadas também por pores indicativas apresentados nos gráficos dos resultados conforme ilustrado na Quadro 1.

Quadro 1: Faixas de valores encontrados para a distância $L$ do AIQA.

\begin{tabular}{|l|l|l|l|}
\hline Classe de Qualidade & Compatibilidade com Classes Água Doce - CONAMA & Distância Ln ao Ponto E (AIQA) & Cor indicativa \\
\hline Não Disponível (ND) & - & - & \\
\hline Muito boa (MB) & Classe 1 & $0,00<A I Q A \leq 0,20$ & \\
\hline Boa & Classe 2 & $0,20<A I Q A \leq 0,20$ & \\
\hline Pouco Poluída & Classe 3 & $0,40<A I Q A \leq 0,60$ & \\
\hline Medianamente Poluída & Classe 3 & $0,60<A I Q A \leq 0,80$ & \\
\hline Poluída & Classe 4 & $0,80<A I Q A \leq 1,00$ & \\
\hline Muito Poluída & Fora de Classe & $1,00<A I Q A \leq 1,20$ & \\
\hline Extremamente Poluída & Fora de Classe & AIQA $\geq 1,20$ & \\
\hline
\end{tabular}

Fonte: IAP (2009).

Em função da comparação dos dados dos Parâmetros de Água com os dados demográficos e de uso do solo, foram enfatizados nas análises os dados dos anos censitários de 1991, 2000, 2010 e do ano de 2016, a fim de se obter o dado de comparação com resultados mais recentes, sendo apresentados nos resultados somente os dados dos Parâmetros de Água para estes anos. Contudo, são apresentados nos resultados os Gráficos com a Evolução da Qualidade da Água, elaborados a partir dos dados históricos disponíveis para cada Estação de Amostragem, entre os anos de 1991 a 2016.

Em relação aos parâmetros de qualidade da Qualidade da água, por se tratarem de dados históricos do IAP do período de 1991 a 2016, houve para este período dois diferentes instrumentos normativos que regulamentam os critérios para o enquadramento dos corpos d'água, as Resoluções no 357 de 2005 e no 20 de 1986 do CONAMA. Nesse sentido, a fim de se obter a comparação dos resultados nos anos avaliados em relação aos parâmetros que não tiveram atendimento dos limites estabelecidos para a Classe do Corpo d'agua, e para que fosse possível ser utilizado um único critério para todo o período estudado, foi utilizada a resolução no 357 de 2005 do CONAMA.

Segundo a Portaria SUDERHSA nº 004 de 21 de março de 1991, os cursos d'água da bacia do Iguaçu estão enquadrados na Classe 2, consequentemente o rio Passaúna e seus afluentes pertencem a esta classe. Após a barragem, para as estações de Amostragem Al 37, considera-se a Classe 3, conforme disposto na Resolução no 4 de 2013 do COALIAR, a qual aprovou a proposição de atualização do enquadramento dos corpos de água, para as Bacias do Alto Iguaçu e Afluentes do Alto Ribeira, em classes, de acordo com os usos preponderantes.

Devido à ausência do parâmetro Coliforme Total na referida resolução, quando este foi verificado nos dados observados entre os anos de 1991 até 2004, excepcionalmente, foi utilizado os limites estabelecidos para coliformes totais do instrumento vigente nesse período, a Resolução no 20 de 1986 do CONAMA.

\section{Estimativa da população nas áreas das sub-bacias}

A partir dos dados de população dos setores censitários do IBGE (2010), calculou-se a população das 
sub-bacias com base nos somatórios das densidades populacionais de cada Setor Censitário dentro de seus limites. Nas áreas em que os perímetros não são coincidentes utilizou-se o fator de proporcionalidade em função da área de ocupação do setor censitário no interior da sub-bacia.

A população e da densidade demográfica apresentados nos Gráficos 5, 8 ,11 e 14 foram obtidos computacionalmente com o auxílio do Software Arcview 3.2 aplicando-se a interseção entre dados de área das sub-bacias e os dados de população dos setores censitários, totalizando-se para cada ano, a população por sub-bacia.

Considerando que os valores informados pelo IBGE para a população nos municípios para o ano de 2016 são estimativos e, por conseguinte, não se tem a informação da população nos Setores Censitários, para o cálculo da população das sub-bacias neste ano utilizou-se a Método da Projeção Aritmética.

\section{Uso do solo nas sub-bacias}

Para a determinação dos usos do solo nas Sub-bacias, nos diversos anos, adotou-se as classes que foram definidas pelo levantamento do uso do solo do ano de 2000 pela SUDERHSA (2000), as quais gerados a partir de técnicas de sensoriamento remoto e interpretação das fotografias aéreas digitais ortorretificadas (ortofotos).

Para a implementação nesse trabalho, as classes de uso do solo da (SUDERHSA, 2000) foram agregadas, gerando uma nova classificação apresentada no Quadro 2, na qual a exemplo de vegetação não rasteiras, foram adotadas uma única classe que é Vegetação Arbórea ou Arbustiva.

Quadro 2: Classificações de Uso e Ocupação do Solo.

\begin{tabular}{|l|l|l|}
\hline $\begin{array}{l}\text { Grup } \\
\mathbf{o}\end{array}$ & Bacia do Alto Iguaçu (SUDERHSA, 2000) & $\begin{array}{l}\text { Classificações de Uso do } \\
\text { Solo }\end{array}$ \\
\hline A & $\begin{array}{l}\text { Área Urbana Alta, Área Urbana Baixa, Área Urbana Media, Loteamentos e Vila (Perímetro } \\
\text { Rural) }\end{array}$ & Área urbanizada ou Vila \\
\hline B & Campo, Solo Exposto e Afloramento Rochoso & Área Rural de Campo \\
\hline C & Cultura Temporária e Cultura Permanente & Área de Cultivo \\
\hline D & $\begin{array}{l}\text { Armazéns/Silos, Aterro Sanitário/Industrial, Granja, Área Industrial, Lixão, Mineração /Areia, } \\
\text { Mineração /Outros }\end{array}$ & Área Industrial \\
\hline E & Vegetação Arbórea Natural, Plantada, Vegetação Arbustiva Natural & $\begin{array}{l}\text { Vegetação Arbórea ou } \\
\text { Arbustiva }\end{array}$ \\
\hline F & Água e Área Alagada & Água ou Área alagada \\
\hline
\end{tabular}

Fonte: base em SUDERHSA (2000).

Foram levantadas para cada sub-bacia, através de conceitos fotointerpretação simplificados, os padrões de uso descritos no Quadro 2: Área urbanizada ou; Campo ou Pastagem; Área de Cultivo; Área Industrial; Vegetação Arbórea ou Arbustiva; e; Área alagada ou Água.

Cabe destacar que as áreas denominadas como Vilas, são aglomerações de habitações nas áreas rurais. Para designar a ocorrência de novas áreas de Vilas para os anos de 2010 e 2016, em relação as já observadas pela SUDERSHA no ano de 2000, buscou-se identificar as regiões que apresentaram número de edificações aglomeradas maior que 10. 


\section{Área de abrangência da rede de coleta de esgoto (RCE)}

A partir dos dados espaciais de atendimento da Rede de Coleta de Esgoto (RCE) disponibilizados pela SANEPAR (2018) em arquivo shape, obtiveram-se as extensões dessa rede implantadas em cada ano na área da Bacia do Passaúna. A área de abrangência foi estimada com auxílio dos softwares ArcView GIS 3.2. e QGIS 3.6.

Definiu-se como raio de alcance da RCE a largura padrão de 75 metros, para a qual foi considerada que a caixa da via pública tem uma largura de 15 metros e que essa rede pode atender aos lotes dos dois lados da via, para os quais se estimou uma profundidade de 30 metros. Essa medida teve por base o lote padrão de $360 \mathrm{~m}^{2}$, sendo $12 \mathrm{~m}$ de testada por 30 metros de profundidade, para as zonas de predominância residencial de baixa densidade de ocupação, baseado no que a Lei no 9.800 de 2000 .

\section{RESULTADOS}

\section{Resultados para a sub-bacia SB 28}

Para a Estação de Amostragem Al 28, obtiveram-se os dados dos parâmetros de Qualidade da água entre os anos de 1991 a 2012. No Gráfico 1 é representada a evolução da qualidade da água entre os anos de 1991 a 2012 para a Estação de Amostragem Al 27, em função do indicador na AIQA e das concentrações para: Nitrito, Nitrato, Nitrogênio amoniacal e Fósforo Total.

No Gráfico 2 é representada a evolução da qualidade da água entre os anos de 1991 a 2012 para a Estação de Amostragem Al 27, em função do indicador na AIQA e das concentrações para Oxigênio Dissolvido DBO (Demanda Biológica de Oxigênio) e DQO (Demanda Química de Oxigênio).

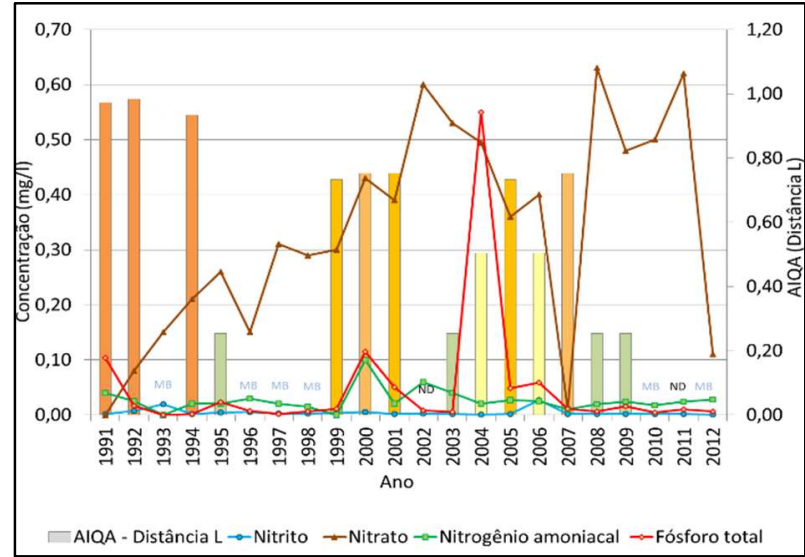

Gráfico 1: Evolução da Qualidade da Água na Estação de Amostragem Al 27.

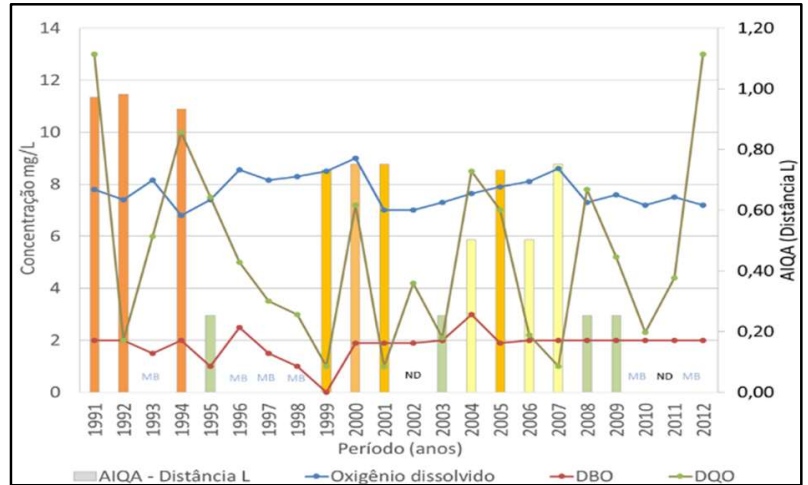

Gráfico 2: Evolução da Qualidade da Água na Estação de Amostragem Al 27.

Para a Estação de Amostragem Al 28, obtiveram-se os dados dos parâmetros de Qualidade da água entre os anos de 1991 a 2016. No Gráfico 3, são apresentadas as variações das concentrações para os parâmetros Nitrito, Nitrato e Nitrogênio Amoniacal e Fósforo total em função do indicar da AIQA.

No Gráfico 4 é representada a evolução da qualidade da água, em função do indicar da AIQA e das variações nas concentrações para os parâmetros Oxigênio Dissolvido, DBO e DQO, entre os anos de 1991 a 2016 para a Estação de Amostragem Al 28. 


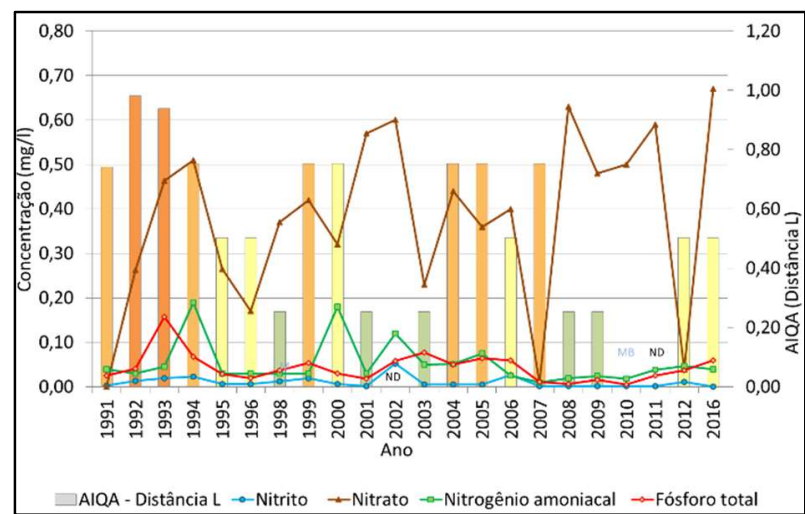

Gráfico 3: Evolução da Qualidade da Água na Estação de Amostragem Al 28.

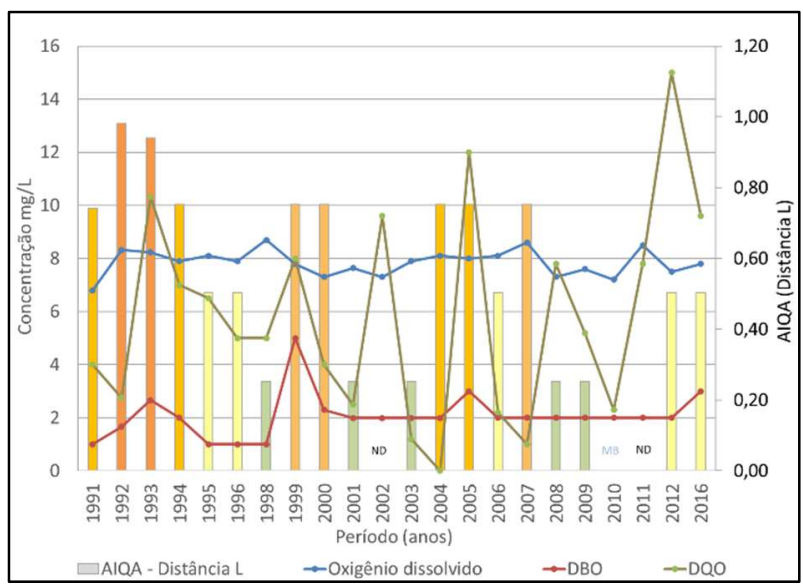

Gráfico 4: Evolução da Qualidade da Água na Estação de Amostragem Al 28.

No Gráfico 5, são apresentadas as variações do uso do solo da abrangência da Rede de Coleta de Esgoto (RCE) e da densidade demográfica na Sub-bacia SB 28, para os anos censitários de 2000, 2010 e para o ano de 2016, bem como o indicador da AIQA para a estação de amostragem Al 28 nos anos citados, conforme os valores foram apresentados no Gráficos 3 e 4.

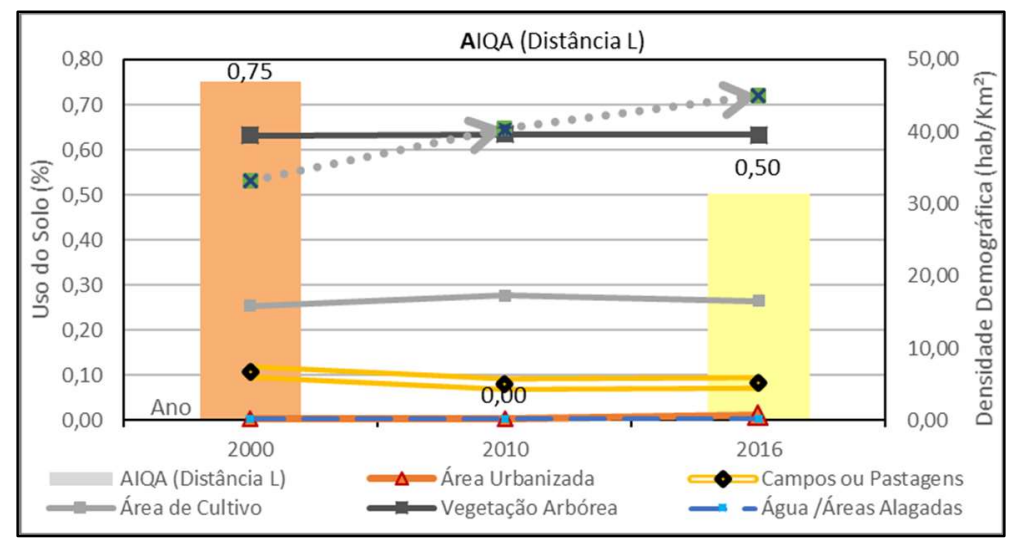

Gráfico 5: Variação do Uso do Solo e da Densidade Demográfica na SB 28.

\section{Resultados para a sub-bacia SB 36}

A Estação de Amostragem Al 36 foi escolhida em função de ser um ponto de referência de qualidade da água para o escoamento do segmento anterior da sub-bacia SB 37 e consequentemente da estação de amostragem Al 37, no exutório da Sub-bacia SB 37. Para a estação de amostragem Al 36 obtiveram-se os dados dos parâmetros de Qualidade da água entre os anos de 1991 a 2012. No Gráfico 6 é representada a evolução da qualidade da água entre os anos de 1991 a 2012 para a Estação de Amostragem Al 36, em função do indicador na AIQA e das concentrações para: Nitrito, Nitrato, Nitrogênio amoniacal e Fósforo Total.

No Gráfico 7 é representada a evolução da qualidade da água entre os anos de 1991 a 2012 para a Estação de Amostragem Al 36, em função do indicador na AIQA e das concentrações para DBO e DQO.

No Gráfico 8, são apresentadas as variações do uso do solo da abrangência da Rede de Coleta de Esgoto (RCE) e da densidade demográfica na Sub-bacia SB 28, para os anos censitários de 2000, 2010 e para o ano de 2016, bem como o indicador da AIQA para a estação de amostragem Al 28 nos anos citados, conforme os valores foram apresentados no Gráficos 3 e 4. 


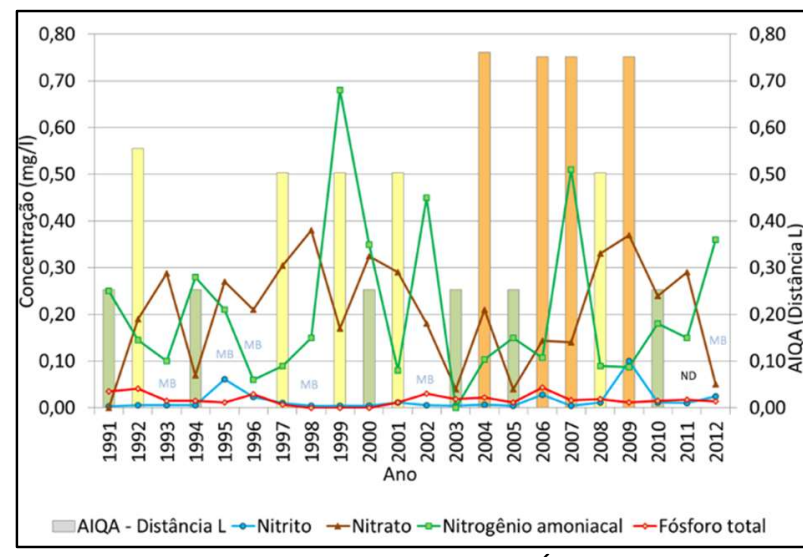

Gráfico 6: Evolução da Qualidade da Água na Estação de Amostragem Al 36.

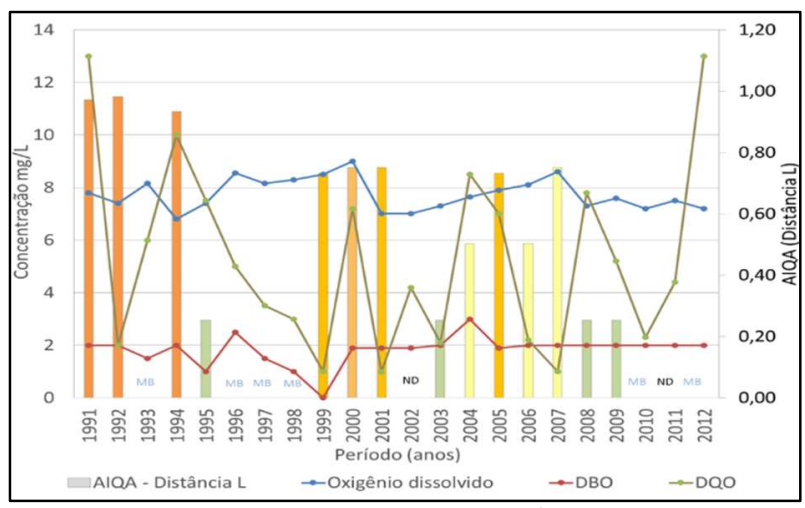

Gráfico 7: Evolução da Qualidade da Água na Estação de Amostragem Al 36.

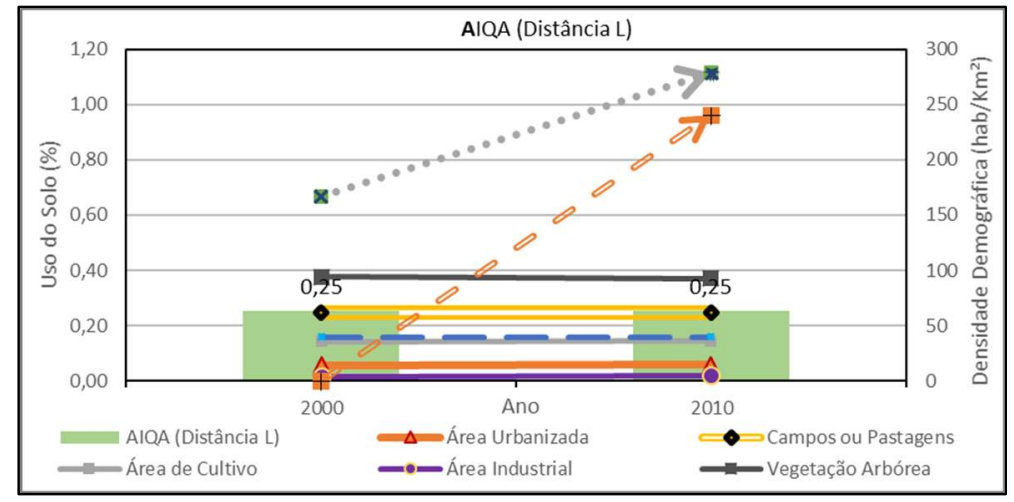

Gráfico 8: Variação do Uso do Solo e da Densidade Demográfica na SB 36.

\section{Resultados para a sub-bacia SB 37}

Para a Estação de Amostragem Al 37, obtiveram-se os dados dos parâmetros de Qualidade da Água entre os anos de 1991 a 2010. No Gráfico 9, são apresentadas as variações das concentrações para os parâmetros Nitrito, Nitrato e Nitrogênio Amoniacal e Fósforo total em função do indicar da AIQA.

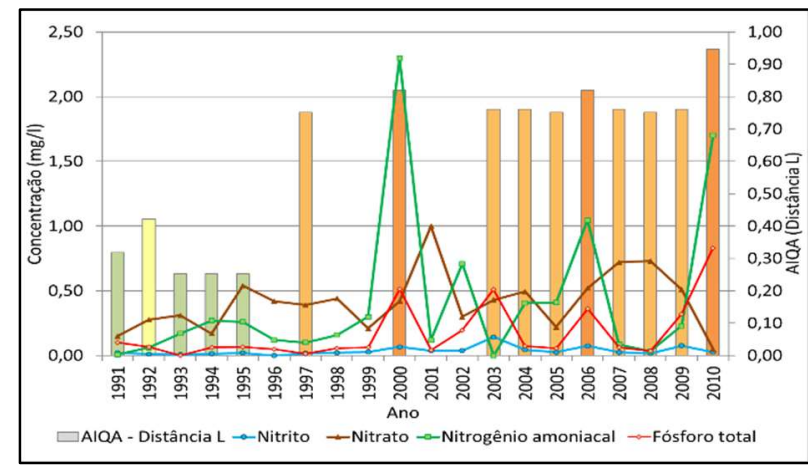

Gráfico 9: Evolução da Qualidade da Água na Estação de Amostragem Al 37.

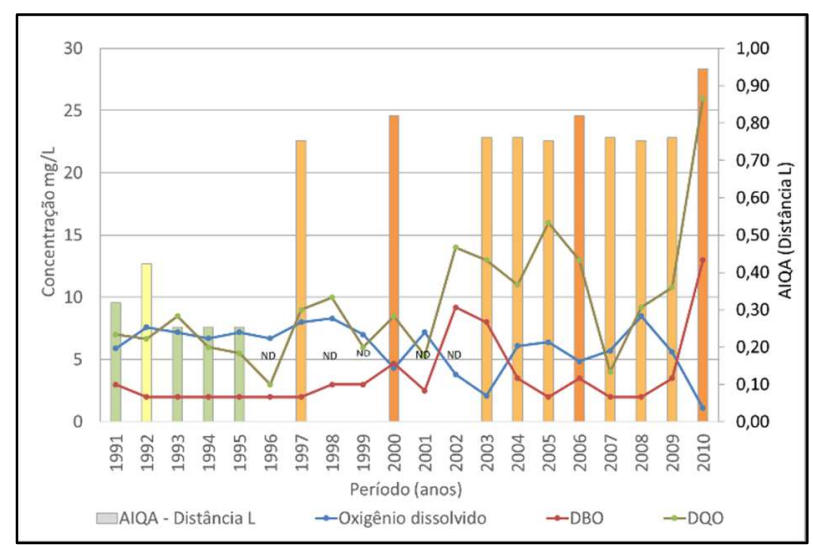

Gráfico 10: Evolução da Qualidade da Água na Estação de Amostragem Al 37.

No Gráfico 10 é representada a evolução da qualidade da água, em função do indicar da AIQA e das variações nas concentrações para os parâmetros Oxigênio Dissolvido, DBO e DQO, entre os anos de 1991 a 2010 para a Estação de Amostragem AI 37.

No Gráfico 11, são apresentadas as variações do uso do solo da abrangência da Rede de Coleta de Esgoto (RCE) e da densidade demográfica na Sub-bacia SB 28, para os anos censitários de 2000 e 2010, bem 
como o indicador da AIQA para a estação de amostragem AI 28 nos anos citados, conforme os valores foram apresentados no Gráficos 9 e10.

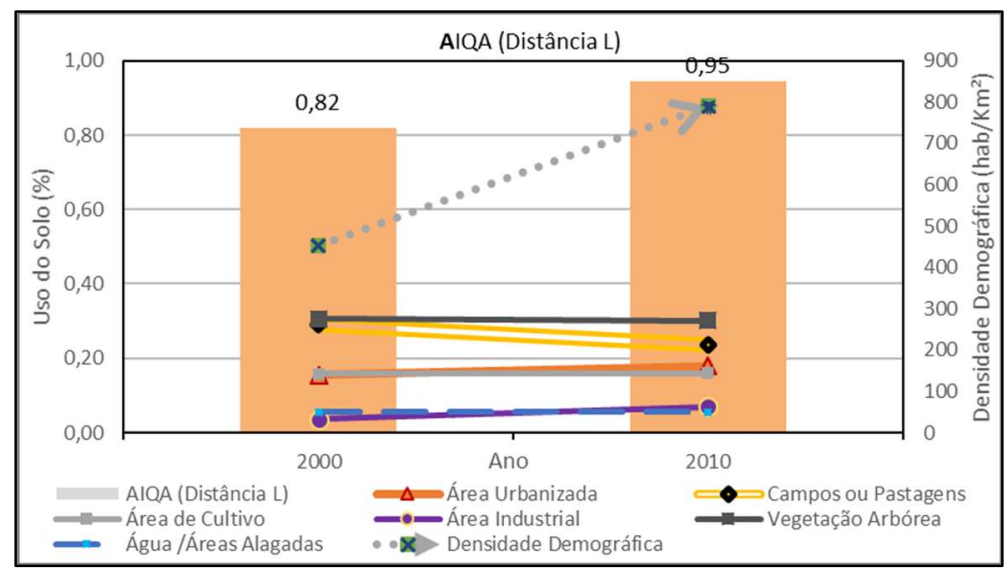

Gráfico 11: Variação do Uso do Solo e da Densidade Demográfica na SB 37.

\section{Resultados para a sub-bacia SB 11}

Para a Estação de Amostragem Al 11, obtiveram-se os dados dos parâmetros de Qualidade da água entre os anos de 1991 a 2016. No Gráfico 12, são apresentadas as variações das concentrações, neste período, para os parâmetros Nitrito, Nitrato e Nitrogênio Amoniacal e Fósforo total em função do indicar da AIQA.

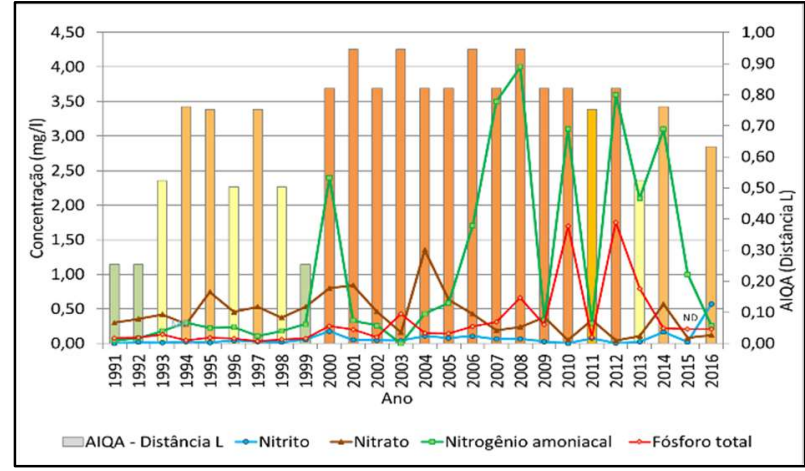

Gráfico 12: Evolução da Qualidade da Água na Estação de Amostragem Al 11.

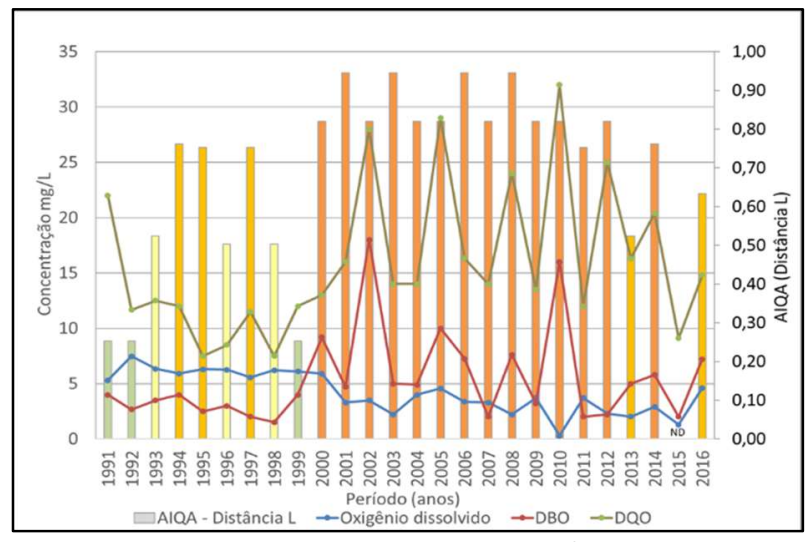

Gráfico 13: Evolução da Qualidade da Água na Estação de Amostragem Al 11.

No Gráfico 13 é representada a evolução da qualidade da água entre os anos de 1991 a 2016 para a Estação de Amostragem Al 36, em função do indicador na AIQA e das concentrações para OD, DBO e DQO.

Para os anos de 2000, 2010 e 2016, as variações do uso do solo e da abrangência da Rede de Coleta de Esgoto (RCE) e da densidade demográfica na Sub-bacia SB 11, são representadas no Gráfico 14 em função do indicador da AIQA para a estação de amostragem AI 11, conforme os valores apresentados nos Gráficos 12 e 13. 


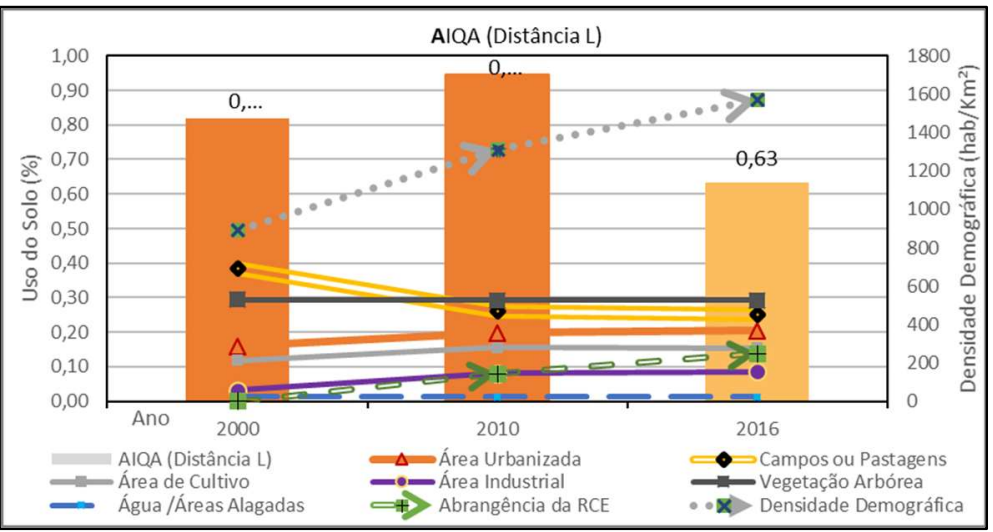

Gráfico 14: Variação do Uso do Solo e da Densidade Demográfica na SB 11.

\section{DISCUSSÃO}

\section{Discussões para a sub-bacia SB 28}

Referente a sub-bacia SB 28, as análises foram realizadas com base nos resultados no início da área de escoamento através da Estação de Amostragem Al 27, próxima da área da nascente, bem como da Estação Al 28 que representa a exutório da água da sub-bacia.

Através da comparação entre os parâmetros apresentados nos Gráficos 1 e 2, observa-se que as variações apresentadas para a DBO e DQO, quase sempre estiveram acompanhadas alterações das concentrações de Fósforo Total, Nitrato, Nitrogênio Amoniacal e Nitrito, no mesmo período ou nos anos subsequentes.

Em alguns períodos, a exemplo dos anos 1993, 1999 e 2005, o comportamento verificado pela DBO seguiu o verificado para a DQO. Essas alterações ocorreram frequentemente associadas ao aumento das concentrações de Coliformes fecais ou E. coli.

Verifica-se que a Al 27, apesar estar localizada próxima a nascente do rio Passaúna, apresentou pior condição de qualidade em relação a Al 28 nos anos iniciais. Um indício para essa condição de qualidade na estação Al 27 é o elevado fator de diluição igual a 6 para o ano de 1991 para Daphnia magna. Considerando a APA do Passaúna, foi instituída através do Decreto Estadual do Paraná n 458/1991, no ano de 1991, visto que a presença de Ecotoxicidade diminui após o ano de 1994, assim como a concentração de Coliformes Fecais. Deste modo, pode-se ter como que hipótese a presença atividades nas proximidades da nascente, a qual originavam poluição por elementos tóxicos e Coliformes. De tal modo, devido às restrições de uso e ocupação do solo impostas pela criação da APA essas atividades provavelmente foram descontinuadas.

A Condição de Qualidade na Estação de Amostragem Al 27 após 1994 foi predominantemente 'Boa' ou 'Muito Boa', porém quando foram observados períodos que a condição de qualidade foi 'Medianamente Poluída' ou 'Pouco Poluída', podendo estas variações estarem vinculadas ao aumento dos valores observados para Coliformes e/ou Ecotoxicidade. Na Estação de Amostragem AI 28, também houve melhora na condição de qualidade após 1994, tendo o predomínio das condições de qualidade como 'Medianamente Poluída', mas também havendo registro como 'Pouco Poluída', 'Boa' e 'Muito Boa'.

Quanto ao uso do solo na sub-bacia SB 28 , conforme pode ser observado no Gráfico 5, não houve 
variação significativa das áreas de vegetação arbórea, visto que para o ano de 2010 o percentual de ocupação era de 63,19\% e para o ano de 2016 de 63,38\%. A diminuição das áreas de campos e pastagens foi acompanhada pelo aumento das áreas de cultivo.

A densidade demográfica estimada na sub-bacia SB 28 para o ano de 2000 é de 33,17 habitantes por quilômetro quadrado e no ano de 2016 de 45,00 habitantes por quilômetro quadrado, representando um crescimento populacional nesse período de $35,66 \%$ na área de sub-bacia, conforme representado no Gráfico 5. Esse crescimento está ligado a expansão das aglomerações fora do perímetro urbano do município denominadas como 'Vilas'. Nesses locais, não foi verificado o atendimento da rede coletora de esgoto, podendo este fator representar um indício para a redução da qualidade da água na sub-bacia, principalmente entre os anos de 2010 a 2016.

Visto que para a Sub-bacia SB 28, foi verificado que há um predomínio de ocupação por Vegetação arbórea e de área de cultivo em $26,55 \%$ de sua área e ainda que a qualidade da água na Estação de Amostragem Al 28, em geral, apresentou condição de qualidade superior as demais.

De maneira geral a estação de amostragem Al 27 apresentou melhores indicadores de qualidade da água que a estação de Amostragem Al 28, de 1991 a 2012, período informações disponíveis para ambos os pontos de coleta. Visto que houve aumento da população e da área agricultada, essa variação pode ter contribuída para a diferença na qualidade da água entre os dois pontos

Os resultados para esta sub-bacia corroboram os verificados por Cornelli et al. (2016). Nesse estudo entre as sub-bacias que foram comparadas, a que havia tido a melhor qualidade da água foi a que possuía características predominantemente rurais com aproximadamente $70 \%$ do uso do solo dividido entre atividade agropastoril, (correspondentes as Áreas de campos, pastagens ou cultivo) e mata nativa, exótica ou estepe (correspondentes as áreas de vegetação arbórea ou Arbustiva).

Considerando a Sub-bacia SB 28 possui uma maior ocupação por Vegetação Arbórea, por conseguinte, pode-se inferir que também possua uma vegetação ripária melhor preservada que as demais sub-bacias. Esta constatação pode estabelecer uma relação como o estudo realizado por Tran et al. (2010), que indicou que a presença de uma zona de proteção de riachos entre córregos e áreas agrícolas e urbanas é um fator significativo na redução da contaminação de cargas não pontuais.

Os resultados para esta sub-bacia, apoiam os verificados Huang et al. (2013), no qual os autores verificaram que as áreas florestadas e de pastagem contribuíram para a redução das concentrações de Fósforo Total, Nitrogênio Total e substâncias que consomem oxigênio, desta forma aumentando a concentração de Oxigênio Dissolvido, e, consequentemente, melhorando a qualidade da água.

\section{Discussões para a sub-bacia SB 36}

A Sub-bacia SB 36 foi delimitada a partir da área de contribuição da Estação de Amostragem Al 36, localizada a jusante da Barragem, conforme na figura 1, próximo a Captação para abastecimento público. Para esta Estação de Amostragem Al 36, obtiveram-se os dados entre os anos de 1991 a 2012 de parâmetros de Qualidade da água, visto que após o ano de 2012 as coletas foram descontinuadas. 
Nos anos iniciais, após a inundação da represa que teve início no ano de 1987, houve diminuição do Fósforo total, foram acompanhas pela redução de Coliformes Fecais, após 1992, tendo sido verificada a condição de qualidade da água classificada como 'Boa' ou 'Muito Boa' até 1996.

Em relação ao indicador da Análise Integrada da Qualidade da Água (AIQA), esse indicador teve valores que classificaram a condição da qualidade como classificada como 'Boa', a qual foi tida nessa condição ou como 'Muito Boa' na maior parte do período avaliado, conforme pode ser observado nos Gráficos 6 e 7. Nos anos em que houve diminuição da qualidade, a exemplo do período entre 2004 a 2009, a diminuição da qualidade, ocorre devido ao aumento das concentrações de coliformes fecais e/ou Escherichia Coli.

Em relação ao uso do solo na Sub-bacia SB 36, conforme pode ser observado no Gráfico 8, não ocorreram variações significativas. Para esta sub-bacia a relação entre a qualidade da água e o uso do solo ocorre de modo diferente das demais sub-bacias analisadas, uma vez nesta área há o represamento do Rio Passaúna para a formação do reservatório de abastecimento público de água pela SANEPAR.

Deste modo a comparação entre o uso do solo e qualidade da água na estação de amostragem Al 36 é mais complexa, devido às sabidas diferenças entre os ambientes lóticos e lênticos quanto ao comportamento de sedimentos e nutrientes transportados até esses ambientes, os quais neste último ficam depositados, por exemplo, em sua maioria no fundo de lagos ou represas.

Entretanto, conforme informações de uso do uso apresentadas no gráfico 8, há evidências que a manutenção das condições do uso do solo como a preservação das áreas de vegetação arbórea, contribuiu para a manutenção e/ou para a melhoria da qualidade neste ponto de monitoramento.

O crescimento da densidade demográfica nesta sub-bacia, não foi acompanhado pelo das áreas urbanizadas, indicando que houve um aumento da taxa de ocupação em regiões já afetadas anteriormente por processos de urbanização.

A diminuição das concentrações de Escherichia Coli após o ano de 2010, assinala uma relação com a implantação da Rede de Coleta de Esgoto na área da Sub-bacia ocorrida após o ano de 2007 a qual para o ano de 2010 tinha abrangência 86,94\% das áreas urbanizadas ou industriais. Entretanto, a presença da rede de esgoto não indica necessariamente que as residências circundantes estejam efetivamente ligadas a ela.

\section{Discussões para a sub-bacia SB 37}

Nos Gráficos 9 e o Gráfico 10, pode ser observado que as variações observadas para a DBO e DQO, quase sempre foram acompanhadas pelas as alterações das concentrações de Fósforo Total, Nitrogênio Amoniacal, no mesmo período ou nos anos subsequentes, estando ocorrências registradas juntamente as variações de coliformes Fecais ou E. Coli.

Entre as ocorrências registradas nos anos de 2000 e 2010, pode-se destacar que o aumento das concentrações de Fósforo Total e Nitrogênio Amoniacal. Conforme pode ser observado no Gráfico 10 nos anos de 2000 e 2010, também houve a diminuição das concentrações de Oxigênio dissolvido e a aumento da DQO e da DBO. Essas variações guardam relação com o aumento das concentrações de Coliformes Fecais e Escherichia Coli. A perda de qualidade da água após o ano 2000, indica uma relação com o aumento da 
população na região que, conforme pode ser observado no gráfico 11 a Densidade Demográfica passou de 890,44 no ano 2000 para 1.095,72 habitantes por quilômetro quadrado no ano de 2010, um amento de $38,48 \%$ o qual não foi acompanhado pelo aumento do atendimento da área de abrangência da RCE, que em 2010 era de 5,69\% da área urbanizada.

Os resultados para esta sub-bacia acompanham os observados para a sub-bacia corroboram os verificados por Barbosa (2012) e Huang et al. (2013), que concluíram, respectivamente, que as áreas urbanas, de cultivo e de pastagens, aumentam a poluição hídrica e que indicam que o aumento da área construída tende a degradar a qualidade da água.

\section{Discussões para a sub-bacia SB 11}

Conforme pode ser observado no gráfico 12 e 13, entre os anos de 2000 e 2010, a Condição de qualidade da água na estação de amostragem Al 11 foi considerada 'Poluída', havendo melhoria nos anos de 2013 e em 2016 quando foi classificada como 'Medianamente Poluída'. Entre as variações observadas no Gráfico 12, destaca-se, por exemplo, o comportamento observado no ano de 2010 em que houve aumento das concentrações de Fósforo Total e Nitrogênio Amoniacal, foram de 1,7 e 3,10 mg/L.

Através da comparação entre os gráficos 12 e 13, pode ser observado que as variações observadas para a DBO e DQO, quase sempre foram acompanhadas pelas as alterações das concentrações de Fósforo Total, Nitrogênio Amoniacal, no mesmo período ou nos anos subsequentes, estando ocorrências registradas juntamente as variações de coliformes Fecais ou E. Coli.

A área delimitada por esta Sub-bacia está inserida em sua maioria no município de Araucária. Conforme pode ser observado no Gráfico 14, verifica-se que entre os anos de 2000 a 2016 houve um aumento das áreas urbanizadas, industriais e de cultivo, e, consequentemente, em função da expansão destas áreas houve diminuição das áreas de cultivo, sendo que não foi possível observar nas áreas cobertas por Vegetação Arbórea, que ainda foram verificadas como predominantes na sub-bacia.

A sub-bacia SB 11 tem como áreas urbanizadas parte dos bairros Estação, Fazenda Velha, Boqueirão e Passaúna. Na porção central da sub-bacia, nas proximidades da PR 423, estão instaladas indústrias e empresas majoritariamente do ramo logístico e também do ramo siderúrgico, as quais foram consideradas com áreas industriais

Não obstante o aumento das áreas urbanizadas entre 2000 e 2016, conforme do Gráfico 14, foi diretamente proporcional ao crescimento populacional da região, visto que houve um aumento $76,28 \%$ nesse período. $O$ aumento observado para a população não foi acompanhado da implantação de rede de coleta de esgoto, que no ano de 2016 tinha abrangência de 13,77\% das áreas urbanizadas e indústrias, conforme indicado Gráfico 14.

Não obstante, pode-se inferir que a qualidade da água na Estação de Amostragem Al 11, frequentemente foi pior que a verificada na estação de Amostragem Al 37 que está a sua jusante, indicando que há uma relação entre a perda de qualidade pela presença de fontes poluidoras originadas das atividades desenvolvidas no interior na Sub-bacia SB 11, sendo que essa, entre as sub-bacias analisadas a que possui 
maior percentual de ocupação por áreas urbanizadas e industriais.

Os resultados para a sub-bacia SB 11 acompanham os observados para a sub-bacia SB36 corroboram os resultados obtidos por Barbosa (2012) e Huang et al. (2013), que concluíram que as áreas urbanas, de cultivo e de pastagens, aumentam a poluição hídrica e que indicam que o aumento da área construída tende a degradar a qualidade da água, respectivamente.

\section{CONCLUSÕES}

O presente trabalho identificou em todas as sub-bacias analisadas atividades antrópicas com impacto na qualidade da água. A relação do uso e da ocupação do solo com a qualidade da água na bacia, foi relacionada às fontes pontuais e difusas de contaminação, oriundas de áreas urbanas, indústrias e agrícolas. Observou-se que o crescimento da população, com a expansão das atividades antrópicas sobre as áreas florestadas relaciona-se com a diminuição na qualidade da água. Em todos as sub-bacias verificou-se uma redução na qualidade da água em relação à estação de amostragem do segmento anterior.

Considerando a grande quantidade de parâmetros de qualidade da água disponíveis, visto que o objetivo do trabalho não foi pormenorizar a variação para todas essas informações, e, sim as variações na qualidade da água numa acepção geral, no que concerne ao método da Avaliação Integrada da Qualidade da Água (AIQA), verificou-se a sua importância como um indicador para avaliar a qualidade da água.

Os mecanismos previstos na legislação, assim como o ZEE, com o controle do ordenamento territorial têm forte impacto sobre a qualidade da água. Contudo, nas regiões urbanizadas as maiores fontes de poluentes são as ligações irregulares de esgoto, sendo necessária a expansão do atendimento desse serviço.

A urbanização causa aumento da impermeabilização em função de suas infraestruturas, como pavimentações, construções, pontes, entre outras, que reduzem bastante à infiltração da água das chuvas no solo e aumentam carregamento de poluentes pela drenagem urbana, provocando alterações no ambiente da sub-bacia.

Nas sub- bacia SB 37, que recebe água de boa qualidade do vertedouro da represa, assim como na estação de amostragem SB 11, em seus respectivos exutórios, as Estações de Amostragem Al 37 e Al 11, a perda de qualidade da água frequentemente esteve associada a presença de coliformes fecais e/ou E. coli, indicando assim uma relação entre as áreas urbanizadas como responsável por grande parte do lançamento de esgotos domésticos. Portanto, há indícios de que a diminuição da qualidade nestas bacias hidrográfica tem uma forte relação com os despejos irregulares desses dejetos nos corpos d'agua o que também pode ter ocorrido para a Sub-bacia SB 28, dado que também houve aumento da densidade populacional em sua área, a qual não foi detectada presença do atendimento de Rede de Coleta de Esgoto.

Contudo, dada a proximidade dos corpos d'agua em alguns pontos e áreas de pastagem de propriedades rurais, não se pode descartar a origem de coliformes o escoamento de fezes de animais, bem como lançamento irregular de esgoto das habitações destas áreas, especialmente em relação a sub-bacia Sb 28.

Nas imagens de satélite podem ser verificados processos de urbanização, fora dos perímetros 
urbanos e que, portanto, não obedecem ao zoneamento rural cuja parcela mínima é $20.000 \mathrm{~m}^{2}$, podendo assim ser definidas essas ocupações como irregulares, as quais muitas vezes são verificadas em áreas de restrição à ocupação, definidas pelo Zoneamento Ecológico Econômico da APA do Passaúna. Visto que estas regiões preponderantemente não possuem rede de coleta de esgoto, cabe aventar a influência na qualidade da água gerada por estas ocupações nas áreas de APAS e de mananciais.

Estudos como o realizado por Monaghan et al. (2007), sugerem que através da implementação de melhores práticas de manejo nas atividades do ambiente rural promovem uma melhoria significativa na qualidade da água. Assim, o efeito do escoamento gerado pelos resíduos dessas áreas pode ser diminuído pelo uso de terraceamento, os quais auxiliam na retenção das águas da chuva. A não preservação das matas ciliares pode gerar processos erosivos, que, mesmo pequenos, podem alterar a qualidade do corpo hídrico.

Nas regiões onde há o predomínio da agricultura intensiva e extensiva nas áreas de manancial, a exemplo da Sub-bacia SB 28, são necessárias ações a fim de coibir a utilização defensivos agrícola e a promoção da orientação quanto as melhores práticas para que o uso de fertilizantes, não sejam escoados para os corpos d'água, com o objetivo criar procedimento para diminuir o impacto e controlar as atividades que promovem a perda de qualidade da água.

Verifica-se a importância da disponibilidade de dados históricos de parâmetros de qualidade da água do IAP para o seu monitoramento. Contudo foi identificado ao longo dos anos houve a redução do número de coletas e de pontos de monitoramento na área da bacia hidrográfica estuada, sendo que esta diminuição na quantidade de informações traz prejuízos ao monitoramento, pois este pode trazer ganhos quando associado a mecanismos de fiscalização ambiental.

É de fundamental importância para a redução dos efeitos de degradação da qualidade da água em áreas de mananciais a implementação de instrumentos de fiscalização e de medidas mitigadoras de poluição, tais como: implantação de redes coletoras de esgoto; Controle da expansão das áreas urbanas e industriais; Controle das áreas utilizadas paras as atividades agrossilvopastoris. Controle das áreas de preservação permanente e de fundo de vale; e; Incentivo as boas práticas de manejo agrícola.

Contudo, essas ações só se demostram efetivas se houver a conscientização da população quanto aos efeitos gerados por suas atividades.

\section{REFERÊNCIAS}

ABREU, C. H. M.; CUNHA, A. C.. Qualidade da Água em Ecossistemas Aquáticos Tropicais Sob Impactos Ambientais no Baixo Rio Jari-AP: Revisão Descritiva. Biota Amazônia, v.5, n.2, p.119-131, 2015.

ANDREOLI, C. V.; CARNEIRO, C.. Gestão Integrada de Mananciais de Abastecimento Eutrofizados. Curitiba: SANEPAR, 2005

BARBOSA, L. S.. Análise da qualidade da água e o processo de uso e ocupação das terras na bacia hidrográfica do Rio Pirarara no município de Cacoal-Rondônia. Dissertação (Mestrado em Geografia) - Universidade Federal de Rondônia, Porto Velho, 2012
CONAMA. Conselho Nacional do Meio Ambiente. Resolução n. 357 de 17 de março de 2005. Brasília: Ministério do Meio Ambiente, 2005.

COMEC. Decreto Estadual n. 458 de 1991. Dispõe sobre a criação da Área de Proteção Ambiental localizada nos municípios de Almirante Tamandaré, Araucária, Campo Largo e Curitiba. Curitiba: DOE, 1991.

COMEC. Lei Estadual n.13.027 de 2000. Dispõe sobre a delimitação do perímetro da Área de Proteção Ambiental APA do Passaúna. Curitiba: DOE, 2000. 
CORNELLI, R.; SCHNEIDER, V. E.; BORTOLIN, T. A.; CEMIN, G.; SANTOS, G. M.. Análise da influência do uso e ocupação do solo na qualidade da água de duas sub-bacias hidrográficas do município de Caxias do Sul. Caxias do Sul, 2016.

HUANG, J.; ZHAN, J. YAN, H.; WU, F.; DENG, X.. Evaluation of the impacts of land use on water quality: a case study in the chaohu lake basin. The Scientific World Journal, v.2013, p.7, 2013. DOI: https://doi.org/10.1155/2013/329187

IAP. Instituto Ambiental do Paraná. Relatório do monitoramento da qualidade das águas dos rios da região metropolitana de Curitiba, no período de 1992 a 2005. Curitiba: IAP, 2005.

IAP. Instituto Ambiental do Paraná. Relatório do monitoramento da qualidade das águas dos rios da região metropolitana de Curitiba, no período de 2005 a 2008. Curitiba: IAP, 2009

IAP. Instituto Ambiental do Paraná. Planilhas de dados Históricos e de Parâmetro e Indicadores de Qualidade da Água na Bacia Hidrográfica do Passaúna entre 1991 e 2016. Arquivo digital. Curitiba: IAP, 2018.

IBGE. Instituto Brasileiro de Geografia e Estatística. Informações Censitárias dos anos de 1991, 2000 e 2010. IBGE, 2010.
MONAGHAN, R. M.; WILCOCK, R. J.; SMITH, L. C.; TIKKISETTY, B.; THORROLD, B. S.; COSTALL, D.. Linkages between land management activities and water quality in an intensively farmed catchment in southern New Zealans. Agriculture, Ecosystems \& Environment, v.118, n.1-4, p.211-222, 2007. DOI: https://doi.org/10.1016/i.agee.2006.05.016

SANEPAR. Mapa e dados da Rede da Coleta de Esgoto na área da Bacia Hidrográfica do Rio Passaúna. Curitiba: SANEPAR, 2018.

SUDERHSA. Do Brasil Serviços de Engenharia LTDA. Cartografia 1:10.000, 2000, dados de hidrografia e levantamento aerofotogramétricio (a). SUDERHSA, 2000

SUDERHSA. Do Brasil Serviços de Engenharia LTDA. Uso do solo na bacia do Alto Iguaçu (b). SUDERHSA, 2000.

TRAN, C. P.; BODE, R. W.; SMITH, A.; KELPER, G. S.. Land-Use Proximity as a Basis for Assessing Stream Water Quality in New York State (USA). Ecological Indicators, v.10, n.3, p.727733, 2010. DOI: https://doi.org/10.1016/j.ecolind.2009.12.002

TUNDISI, J. G.. Governança da Água. Belo Horizonte: UFMG, 2013.

A CBPC - Companhia Brasileira de Produção Científica (CNPJ: 11.221.422/0001-03) detém os direitos materiais desta publicação. Os direitos referem-se à publicação do trabalho em qualquer parte do mundo, incluindo os direitos às renovações, expansões e disseminações da contribuição, bem como outros direitos subsidiários. Todos os trabalhos publicados eletronicamente poderão posteriormente ser publicados em coletâneas impressas sob coordenação da Sustenere Publishing, da Companhia Brasileira de Produção Científica e seus parceiros autorizados. Os (as) autores (as) preservam os direitos autorais, mas não têm permissão para a publicação da contribuição em outro meio, impresso ou digital, em português ou em tradução. 